\title{
E-mail use by the faculty members, students and staff of Saudi Arabian and Gulf states Universities
}

\author{
Fahad Alturise Paul R. Calder Brett Wilkinson \\ School of Computer Science, Engineering and Mathematics \\ Flinders University \\ Adelaide, Australia
}

\begin{abstract}
Electronic mail systems (Email) constitute one of the most important communication and business tools that people employ. Email in the workplace can help a business improve its productivity. Many organisations now rely on email to manage internal communications as well as other communication and business processes and procedures. This paper compares email use by university stakeholders (i.e. faculty members, staff and students) between Saudi_Arabia on one hand, and the Gulf States - Qatar, Oman, United Ärab Emirates (UAE) and Bahrain - on the other. A questionnaire that was expertreviewed and pilot-tested, was used to collect data from ten universities in Saudi Arabia and five universities in the Gulf States. Slight differences emerged in the Saudi Arabia and Gulf States universities' stakeholders' use of email in terms of having email, frequency of checking email, and skills in using email. The Saudi Arabian universities must improve their IT infrastructure, including the provision of suitable connection networks and formal training of staff in utilising IT resources. This study's findings aim to advise the Saudi Arabian and Gulf States' universities on their plans and programmes for e-learning and the consolidation of required resources.
\end{abstract}

Keywords - Email; Saudi Arabia; Gulf States

\section{INTRODUCTION}

Email systems constitute the main communication method of electronic learning and are emerging as a strategic business tool. However, electronic learning applications place extra security risks on organisations and businesses due to the problems associated with direct electronic interaction with other entities (Duane and Finnegan 2004). Email systems have traditionally been initiated by IT departments or sections without being part of a business-led strategy. This is despite email having evolved over time to become more of a corporate-wide service (Jackson, Dawson et al. 2001). Through the evolution of email systems, their strategic importance has increased but the benefits of email do not accrue automatically (Stevens and McElhill 2000). Along with increases in electronic business activity and the use of email systems, an increase in employee abuse of email technology has been documented. Virus infection arising from email use and deliberate abuse of email facilities are the leading causes of security breaches, suggesting poor controls and overarching policies that govern email use are to blame (Jackson, Dawson et al. 2003).
Problems emanating from email systems have become critical as technological advances are made towards interorganisational networking. As organisations struggle to derive value from information technologies, particularly in periods of reduced IT budgets (Jackson, Dawson et al. 2002), organisations spend and often waste money buying technology that does not suit the human infrastructure, policies and procedures so that abuses can be prevented or curbed (Burgess, Jackson et al. 2005). For an organisation to shift its focus from operating as a traditional business to an electronic one it must define its practices, procedures and processes so they can be monitored, analysed, and regulated (Jackson, Burgess et al. 2006). Such issues, consequently, inhibit significantly the growth of electronic business. It is imperative that organisations formulate coordinated and comprehensive responses to email systems management. Specifically, businesses and institutions should anticipate the harmful effects of email system abuses or cyber-hacking to prevent them from occurring (Jackson, Dawson et al. 2003).

While the nature and scope of information systems threats have been well documented in the past, there are no real practical measures to stopping or controlling such dangers. Organisations lack analytical tools to examine their practices or to ensure email systems are used only for corporate reasons and not people's preferences (Duane and Finnegan 2004). This paper presents the findings a study that investigated stakeholders in universities in the Gulf States and Saudi Arabia and how they used email systems. The next section examines the frequency of using email generally and in university email systems particularly. This is followed by a discussion of the research method, and a presentation of the research findings. The paper concludes by identifying key factors regarding issues that may influence email usage in Saudi Arabia's universities.

\section{LITERATURE REVIEW}

Even though email usage has been examined for more than twenty years, the differences of email usage between the Saudi Arabian and Gulf States' universities' stakeholders have not been investigated. Current practices in email use re often studied to identify design implications for improving email, but to date studies have not accounted for potential differences among Gulf States users. It can be assumed that the users of an email application are the major source of problems, as they 
create and receive the emails that periodically create problems of security, privacy/confidentiality and professionalism. It is essential to identify the major problems users face with email and then administer training schemes on how to become a more effective and responsible email communicator (Jackson, Burgess et al. 2006).

Research conducted over the past 10 years has focused on the overwhelming nature of electronic mail communication, where stress in the workplace, negative social behaviours, and diminished productivity among knowledge workers have been documented (Jackson, Dawson et al. 2002; Burgess, Jackson et al. 2004; Ducheneaut and Watts 2005; Neustaedter, Brush et al. 2005). Many studies have suggested the positive and negative effects of using email and how this tool helps or impacts on productivity. Duane and Finnegan (2004) reported the negative effects of email use, for example security infractions, productivity drain, non-business communication use, increased cost of usage, profanities, bad news, and illicit use. They reported some solutions to overcome these problems such as proper policy and its practical implementation in the workplace.

Smith (2008) reported that the average employee spends between 90 minutes and two hours per day reading email messages. As the email inbox becomes cluttered with retained emails, incoming messages, irrelevant chain mail, and spam, workers may become victims of email overload or, at a minimum, face rising frustration attempting to manage electronic communication in a disciplined way (Jackson, Dawson et al. 2003, Jackson, Dawson et al. 2003). Many studies on the subject of email overload have emerged in the U.K. (Jackson, Dawson et al. 2003; Jackson, Dawson et al. 2003; Burgess, Jackson et al. 2005), and this subject has now generated more interest in more recent times. It is reported that the average corporate email user sends and receives approximately 156 messages per day, "and this number is expected to grow to about 233 messages a day by 2012" (Radicati Group, Inc., 2008, p. 4). One outcome of the explosive growth in email volume is that businesses and institutions increasingly face key decisions on how to address the email monster (Dudman, 2003). At Loughborough University in England, Jackson conducted a series of research projects (Jackson et al., 2002; 2003a, 2003b; Jackson, Burgess, \& Edwards, 2006) examining email tolerance levels, cost of email to organizations, and reduction of email defects through training of workers.

Issues identified in the studies included the following: poorly written email, email as a distraction, email used improperly (i.e., when face-to-face was warranted), and email carbon copy abuse. Jackson et al. (2003a) found that $65 \%$ of emails sent to recipients failed to provide enough information for the receiver to respond appropriately. Similarly, email messages may not provide the reader with enough information to accurately determine the context or tone of what was being sent (Whittaker, Bellotti et al. 2006). Consequently, the recipient faces additional pressure and frustration attempting to resolve the communication (Burgess, Jackson, \& Edwards, 2004). Other studies show the importance of email in education and how people can benefit by it such as increased productivity, social interaction and well-being (Chase and
Clegg 2011). Some analyses reported the challenges affecting the utilisation of email in education institutions.

\section{OBJECTIVES AND METHODOLOGY OF THE STUDY}

The overall objective of this study was to investigate the problems inherent in ICT systems in Saudi Arabian and Gulf States' universities and try to suggest solutions. One of the most important factors is using communication services such as email among faculty members, administrative staff and students at various universities in these institutions. This study employed a survey to elicit answers to key research questions. A perusal of earlier studies on ICT infrastructure indicates that the questionnaire-based survey has been the most popular method used. Some studies have included open-ended questions (Husain 2001) and selective interviews (Fusayil 2000) to obtain additional data. Most questionnaires have been paper-based enterprises with a few that were web-based (Chu 2002; ur Rehman \& Ramzy 2004; Al-Ansari 2006). For this study it was decided to use a paper-based questionnaire because many respondents of this study will not be able to manage a web-based instrument.

Several studies and a few available questionnaires served as the basis for developing a questionnaire with closed-ended questions. It was divided into five parts; two of them are relevant to this paper. Part I contained questions concerning the demographic characteristics of respondents and Part II consisted of questions concerning university computers and internet, and frequency of using several IT services and their effectiveness. The questionnaire, prepared by the researcher, was reviewed by the supervisor and co-supervisor. Also, it reviewed by a statistical consultant and an expert in English and Arabic languages who can ensure clarity, proper language structure, and elimination of language ambiguities. It was pilottested on 18 students resulting in minor modifications.

An email was sent to 10 universities in Saudi Arabia and 5 universities in the Gulf States, i.e. Oman, Bahrain, Qatar, and UAE. The number of participants was 142 faculty members, 121 staff/administration members and 511 students. A package consisting of information sheets for participants and a questionnaire in the Arabic language was devised for this study.

\section{FINDINGS AND DISCUSSION}

\section{A. Non-users of the Email}

One interesting finding is that, given the prevalence of IT in education and when the university is planning to enter elearning in a big way, $86(11.11 \%)$ of the 774 respondents neither used nor had an email account. This situation is predominant in the Saudi Arabian universities (94.18\%). Of this total, (12.34\%) were faculty members and (20.98\%) were administrative staff. The rest were students and of these only (5.81\%) were from the Gulf States universities. They did not give any reasons for not using email. It seems that they were educated either at a time or in an environment where IT was non-existent and consequently had little or need for any IT in their working or everyday lives. The following sections present the data for this study's questionnaires. 


\section{B. Demographic Characteristics of the Respondents}

Out of the 142 faculty members, 107 (75.35\%) worked in Saudi universities and 35 (24.64\%) were from the Gulf States universities. 106 (74.6\%) were male and 36 (25.4\%) were female. Most of them have $\mathrm{PhD}(50.7 \%)$ and were 45 years old and over (25.4\%) or between 35 and 44 (46.5\%).

Out of the 121 respondents of administrative staff, 95 (78.51\%) were from Saudi universities and 26 (21.48\%) were from the Gulf States universities. 72 (59.5\%) were male and 49 (40.5\%) were female. Most of them have Bachelor degrees (54.5\%) and (19.8\%) have high school or less (54.5\%). Agewise most were between 25 to 34 years old (54.5\%) and $(9.1 \%)$ were 45 years old and over. More than half (57.9\%) have working experience at university between 1 to 5 years although a few (4.1\%) have more than 20 years.

Out of the 511 students, 388 (75.92\%) were from Saudi universities and 123 (24.07\%) were from Gulf States universities. In terms of gender 347 (64.7\%) were male and 189 (35.3\%) were female. Most of them were in their first year of study (34.1\%) and (28.7\%) were in the second year, with $19.6 \%$ in the third year. (80\%) of them live with their family and most of them (89\%) were aged between 18 and 24 .

\section{Email Habits of the Respondents}

TABLE I. UNIVERSITY STAKEHOLDERS WITH ACCESS TO EMAIL

\begin{tabular}{|c|c|c|c|c|}
\hline \multirow{3}{*}{ University Region } & \multicolumn{4}{|c|}{ Email } \\
\hline & \multicolumn{2}{|c|}{ No } & \multicolumn{2}{|c|}{ Yes } \\
\hline & Count & Percent & Count & Percent \\
\hline & \multicolumn{4}{|c|}{ Faculty members } \\
\hline Saudi Universities & 10 & $9.30 \%$ & 97 & $90.70 \%$ \\
\hline \multirow[t]{2}{*}{ Gulf States Universities } & 0 & $0.00 \%$ & 35 & $100.00 \%$ \\
\hline & \multicolumn{4}{|c|}{ Administrative staff } \\
\hline Saudi Universities & 17 & $17.90 \%$ & 78 & $82.10 \%$ \\
\hline \multirow[t]{2}{*}{ Gulf States Universities } & 0 & $0.00 \%$ & 26 & $100.00 \%$ \\
\hline & \multicolumn{4}{|c|}{ Students } \\
\hline Saudi Universities & 54 & $13.90 \%$ & 334 & $86.10 \%$ \\
\hline Gulf States Universities & 5 & $4.10 \%$ & 118 & $95.90 \%$ \\
\hline
\end{tabular}

Table I shows the percentage of university stakeholders who have email accounts either at home or university. About (9\%) of faculty members in Saudi universities do not have an email address while all employees in the Gulf States universities have email addresses. Approximately (18\%) of administrative staff in Saudi universities do not have email address while all staff employees in the Gulf States universities have email addresses. Finally, about (14\%) of students in Saudi universities do not have email addresses compared to about (4\%) in the Gulf States universities not having an email address. The table below shows us that email accounts are more common in the Gulf States universities compared to Saudi Arabia, and this is due to a variety of factors such as familiarity with technology, easy access to IT services and effective role for IT in their day life.

\section{Frequency of Access Email of the Respondents}

Table II shows the frequency of use of emails by stakeholders for different reasons. About (8\%) of Saudi Arabian faculty members never use email or only their check emails once a month or less. About (10\%) of Saudi Arabia faculty members check email once a week compared to about (3\%) of Gulf States faculty members. About (31\%) of Saudi Arabia and Gulf States faculty members check their email once a day. Finally, (52\%) of Saudi Arabian university faculty members use and check email several times per day compared to (66\%) for the Gulf States members. The data indicates that faculty members in the Gulf States universities use email more frequently for their daily activities. This use helps them to understand the benefits of email and how it can be used for learning.

The table also shows that, about (17\%) of Saudi Arabia universities' administrative staff never use email or only check emails once a month or less. About (32\%) of Saudi Arabia administrative staff check emails once a day compared (8\%) of Gulf States universities' administrative staff. Finally, (30\%) of Saudi Arabia universities' administrative staff use and check email several times per day compared to (92\%) for the Gulf States faculty members. This table show how administrative staff in the Gulf States institutions use email more frequently in their daily duties. They understand the benefits of email and how it assists them in their university work.

Finally, about (46\%) of Saudi Arabian university students never use email or only check their emails once a month or less compared to (26\%) in the Gulf States universities. About (19\%) of Saudi Arabian students check their emails once a week compared to (14\%) of the Gulf States students. Finally, about (23\%) of Saudi Arabian students use and check email several times per day compared to (46\%) of the Gulf States students. The data suggests that students in the Gulf States universities use email more frequently than Saudi students. This use also helps them to understand the benefits of email and its applicability to their learning. This use of email could be due to faculty encouragement or the university system which compels to understand emails in everyday transactions.

\section{E. Having and Frequency of Access University Email of the Respondents}

Table III shows the number of stakeholders who have access to university email system and their frequency of use. Five percent of Saudi Arabia university faculty members state that the email system is not available and if it is available (9\%) of them never use it. Furthermore (17\%) of Saudi Arabian faculty members use email university compared to (3\%) of faculty members in the Gulf States. In Saudi Arabia (24\%) of faculty members use email system in university occasionally to (6\%) of faculty members in the Gulf States universities. Finally, (46\%) of Saudi Arabian faculty members use university email system frequently compared it to (92\%) of faculty members in the Gulf States. 
TABLE II. UNIVERSITY STAKEHOLDERS' FREQUENCY OF CHECK EMAIL

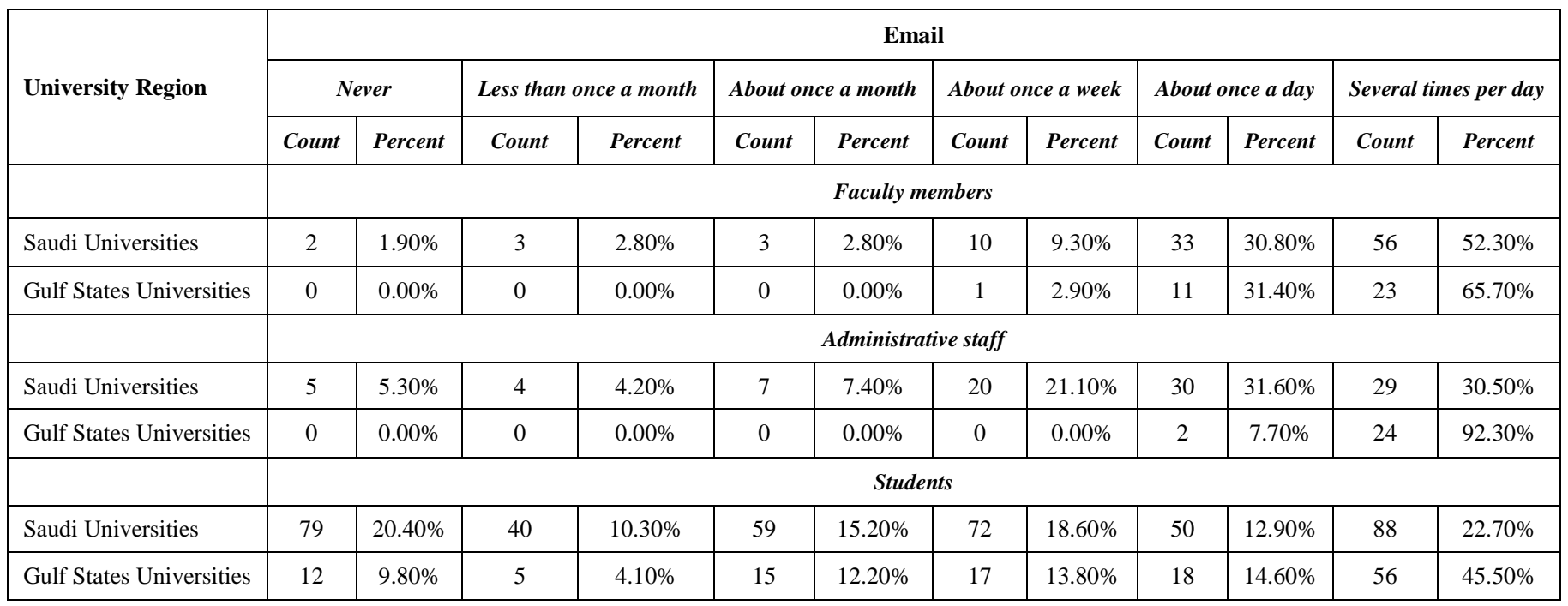

These statistics indicate that faculty members in the Gulf States universities use the email system more frequently and this may be due to more proactive university IT policies, support from decision-makers and people simply being used to working with email systems. The Saudi Arabian universities' problems stem from the lack of IT services, lack of infrastructure, lack of motivation, lack of skills and others.

According to (10\%) of Saudi Arabian universities' administrative staff the email system is not available. Another (5\%) have a university email account but never use the email system. Moreover, (23\%) of Saudi Arabian universities' administrative staff use email university rarely while (25\%) use email university occasionally. Furthermore (37\%) of Saudi Arabian universities' administrative staff use university email system frequently compared to all (100\%) of Gulf States universities' staff using email frequently. This complete participation could be due to better policing of the university email system and the fact that Gulf States university staff are comfortable in contacting stakeholders by email.

Finally, (11\%) of Saudi Arabian universities' students point out the university email system is not available and if it is available (14\%) of them have never used it. This contrasts with less than (1\%) in Gulf state countries universities do not have this service and about (3\%) who never use if it is available. Moreover, (25\%) of students in Saudi Arabian universities' use email university rarely compared to (7\%) of Gulf States universities' students. Twenty percent of students in Saudi Arabian universities use the email system occasionally compared to (12\%) in the Gulf States institutions. Furthermore (30\%) of students in Saudi Arabian universities' use the email system frequently compared to (77\%) for the Gulf state universities' students.

TABLE III. UNIVERSITY STAKEHOLDERS’ USING UNIVERSITY EMAIL

\begin{tabular}{|c|c|c|c|c|c|c|c|c|c|c|c|c|}
\hline \multirow{3}{*}{ University Region } & \multicolumn{12}{|c|}{ University email system } \\
\hline & \multicolumn{2}{|c|}{ N/A } & \multicolumn{2}{|c|}{ Never } & \multicolumn{2}{|c|}{ Very Rare } & \multicolumn{2}{|c|}{ Rare } & \multicolumn{2}{|c|}{ Occasional } & \multicolumn{2}{|c|}{ Frequent } \\
\hline & Count & Percent & Count & Percent & Count & Percent & Count & Percent & Count & Percent & Count & Percent \\
\hline & \multicolumn{12}{|c|}{ Faculty members } \\
\hline Saudi Universities & 5 & $4.70 \%$ & 9 & $8.40 \%$ & 2 & $1.90 \%$ & 16 & $15.00 \%$ & 26 & $24.30 \%$ & 49 & $45.80 \%$ \\
\hline \multirow[t]{2}{*}{ Gulf States Universities } & 0 & $0.00 \%$ & 0 & $0.00 \%$ & 1 & $2.90 \%$ & 0 & $0.00 \%$ & 2 & $5.70 \%$ & 32 & $91.40 \%$ \\
\hline & \multicolumn{12}{|c|}{ Administrative staff } \\
\hline Saudi Universities & 9 & $9.50 \%$ & 5 & $5.30 \%$ & 9 & $9.50 \%$ & 13 & $13.70 \%$ & 24 & $25.30 \%$ & 35 & $36.80 \%$ \\
\hline \multirow[t]{2}{*}{ Gulf States Universities } & 0 & $0.00 \%$ & 0 & $0.00 \%$ & 0 & $0.00 \%$ & 0 & $0.00 \%$ & 0 & $0.00 \%$ & 26 & $100.00 \%$ \\
\hline & \multicolumn{12}{|c|}{ Students } \\
\hline Saudi Universities & 40 & $10.30 \%$ & 54 & $13.90 \%$ & 33 & $8.50 \%$ & 68 & $17.50 \%$ & 76 & $19.60 \%$ & 117 & $30.20 \%$ \\
\hline Gulf States Universities & 1 & $0.80 \%$ & 4 & $3.30 \%$ & 4 & $3.30 \%$ & 5 & $4.10 \%$ & 15 & $12.20 \%$ & 94 & $76.40 \%$ \\
\hline
\end{tabular}


TABLE IV. UNIVERSITY STAKEHOLDERS’ EMAIL SYSTEM SKILLS

\begin{tabular}{|c|c|c|c|c|c|c|c|c|c|c|}
\hline \multirow{3}{*}{ University Region } & \multicolumn{10}{|c|}{ Email } \\
\hline & \multicolumn{2}{|c|}{ Non User } & \multicolumn{2}{|c|}{ Beginner } & \multicolumn{2}{|c|}{ Moderate } & \multicolumn{2}{|c|}{ Competent } & \multicolumn{2}{|c|}{ Expert } \\
\hline & Count & Percent & Count & Percent & Count & Percent & Count & Percent & Count & Percent \\
\hline & \multicolumn{10}{|c|}{ Faculty members } \\
\hline Saudi Universities & 0 & $0.00 \%$ & 1 & $0.90 \%$ & 9 & $8.40 \%$ & 30 & $28.00 \%$ & 67 & $62.60 \%$ \\
\hline \multirow[t]{2}{*}{ Gulf States Universities } & 1 & $2.90 \%$ & 0 & $0.00 \%$ & 0 & $0.00 \%$ & 9 & $25.70 \%$ & 25 & $71.40 \%$ \\
\hline & \multicolumn{10}{|c|}{ Administrative staff } \\
\hline Saudi Universities & 1 & $1.10 \%$ & 4 & $4.20 \%$ & 11 & $11.60 \%$ & 36 & $37.90 \%$ & 43 & $45.30 \%$ \\
\hline \multirow[t]{2}{*}{ Gulf States Universities } & 0 & $0.00 \%$ & 1 & $3.80 \%$ & 0 & $0.00 \%$ & 6 & $23.10 \%$ & 19 & $73.10 \%$ \\
\hline & \multicolumn{10}{|c|}{ Students } \\
\hline Saudi Universities & 27 & $7.00 \%$ & 23 & $5.90 \%$ & 67 & $17.30 \%$ & 116 & $29.90 \%$ & 155 & $39.90 \%$ \\
\hline Gulf States Universities & 2 & $1.60 \%$ & 3 & $2.40 \%$ & 13 & $10.60 \%$ & 36 & $29.30 \%$ & 69 & $56.10 \%$ \\
\hline
\end{tabular}

\section{F. Skills of Using Email of the Respondents}

Table IV summarises the skills of using email from the university stakeholders' point of view. In Saudi Arabia (1\%) of faculty members are at the beginner or learning stage compared to (3\%) in the Gulf States universities. It is evident that (8\%) of Saudi Arabian faculty members have a moderate level of skills of using email.

Also, (26\%) of both Saudi Arabian and Gulf States faculty members have a competent level of skills of using email. Finally, (63\%) of Saudi Arabia faculty members are expert in using email compare to (72\%) of faculty members in the Gulf States. It is evident that faculty members in Saudi Arabia and Gulf States universities have the same or similar level of skills in using email. However, this still means that they need training courses to motivate them and educate them in improving email skills. On the other hand, (5\%) of Saudi Arabian administrative staff point out that their skills are at the beginner stage or less compared to (4\%) in the Gulf States universities. For the Saudi Arabian administrative staff, (12\%) have moderate level of skills of using email, and (38\%) of Saudi Arabia faculty members have a competent skill level compared to (23\%) of administrative staff in the Gulf States. Finally, (45\%) of Saudi Arabian administrative staff are expert in using email compare to (73\%) of administrative staff in the Gulf States.

These statistics reveal that administrative staff in Saudi Arabian institutions have less skills or expertise than administrative staff in the Gulf States. This means that Saudi Arabian university administrative staff require good quality training courses and support to overcome difficulties and to improve how they employ email for designated tasks. Finally, (13\%) of Saudi Arabia students point out that their skills in using email are at the beginner level or less compared to (4\%) in the Gulf States universities. Apparently, (17\%) of Saudi Arabian students have a moderate level of skills of using email compared to $(11 \%)$ of students in the Gulf States. In both
Saudi Arabia and the Gulf Staters, (29\%) of students have a competent level of skills when using email. It emerges that (40\%) of Saudi Arabian students are expert in using email compared to (56\%) of students in the Gulf States. This indicates that Saudi Arabian students have poorer skills compared to those in the Gulf States universities. They need more encouragement from faculty members to communicate via email and it is apparent that Saudi universities must overcome this dilemma. Faculty members have to help students facilitate the email system at the beginning of each semester.

Saudi Arabian university stakeholders participate less in email compared to their counterparts in the Gulf States, and are less skilled as well. In particular the administrative staff's use of email is lower in Saudi Arabia because it has not been actively promoted or implemented. It is paramount that the decision-makers and senior executives in Saudi Arabia's universities lead the way in changing how staff work with modern electronic technologies and Internet systems that incorporate email services.

\section{CONCLUSIONS AND RECOMMENDATIONS}

The analysis presented above shows that there is a difference in email usage among faculty members, administrative staff and students of Saudi Arabia and Gulf States universities. However, if the results of this study are viewed in light of the universities' recent interest in promoting e-learning, then the level of interest, nature of use and ability of these respondents seem to fall short of the requirements of developing e-learning via using email services.

The respondents' dependence on learning by themselves how to use email indicates a deficiency in formal training opportunities. A greater use of email by these respondents for personal objectives, be they communication, research or writing, and little interest shown in using it for teaching and classroom work points to another critical gap that contradicts 
or undermines the university's plans to emphasise IT's place in teaching and learning activities.

An encouraging sign in the findings is the awareness shown by participants of the usefulness of the Internet and its resources for academic work and for identifying concrete problems they face while using these resources. Participants are mindful of the need to upgrade their Internet expertise and experience in online searching.

The observations made above have serious implications for the universities' future academic learning and development plans. These demand immediate and serious attention in the following areas:

- Identification and preparation of plans for upgrading, as soon as possible, the IT infrastructure including libraries, to bring them to a level compatible with the requirements of intensive IT-based teaching, learning and research.

- Conducting a "training needs analysis" which will identify gaps in IT use skills among the faculty, staff, and students.

- $\quad$ Developing formal and differential training packages based on the results of the training needs analysis to improve IT competencies.

- University management must improve their IT applications, staff IT competence and qualification, and remotely available information resources, and focused formal training programmes essential for these resources and services.

The results of this survey point to some issues on which further research is required. There is a need to measure email use skills of faculty, staff and students in a more concrete manner so that differentiated training packages can be prepared for various groups. In other words, a training needs analysis of various segments of the academic population should be done. Prior to that, students' use of the Internet needs to be analysed. The training programs offered by the universities should be analysed in terms of their effectiveness. There is also a need to investigate the level of information evaluation skills of email users and create an awareness of the importance of this activity in selecting and using internet resources for teaching, learning and research. Also, university decision-makers have to encourage and motivate faculty members and staff to increase their use of IT services and email systems. They can do this by establishing training courses, reducing the teaching load, increase salaries and other methods.

\section{ACKNOWLEDGMENT}

This research is supported by Saudi Arabia Cultural Mission and Flinders University.

\section{REFERENCES}

[1] Al-Ansari, H. (2006). "Internet use by the faculty members of Kuwait University." Electronic Library, The 24(6): 791-803.

[2] Burgess, A., et al. (2004). "The effectiveness of training in reducing email defects."

[3] Burgess, A., et al. (2005). "Email training significantly reduces email defects." International Journal of Information Management 25(1): 71-83.
[4] Chase, N. M. and B. Clegg (2011). "Effects of Email Utilization on Higher Education Professionals." International Journal of Technology and Human Interaction (IJTHI) 7(4): 31-45.

[5] Chu, Y.-h. (2002). Factors related to adoption of internet resources in instruction by faculty at the Pennsylvania State University, Pennsylvania State University.

[6] Duane, A. and P. Finnegan (2004). Managing email usage: A cross case analysis of experiences with electronic monitoring and control. Proceedings of the 6th international conference on Electronic commerce, ACM.

[7] Ducheneaut, N. and L. A. Watts (2005). "In search of coherence: a review of e-mail research." Human-Computer Interaction 20(1-2): 1148.

[8] Fusayil, A. (2000). The adoption of the internet by faculty members at Ohio University, Ohio University, June.

[9] Husain, S. P. R. (2001). "Adoption of the internet as a teaching and learning tool: patterns of use, motivators and barriers among outstanding faculty in community colleges."

[10] Jackson, T., et al. (2001). "The cost of email interruption." Journal of Systems and Information Technology 5(1): 81-92.

[11] Jackson, T., et al. (2003). "Reducing the effect of email interruptions on employees." International Journal of Information Management 23(1): 55-65.

[12] Jackson, T. W., et al. (2006). "A simple approach to improving email communication." Communications of the ACM 49(6): 107-109.

[13] Jackson, T. W., et al. (2002). "The cost of email within organizations." Strategies for eCommerce Success: 307.

[14] Jackson, T. W., et al. (2003). "Understanding email interaction increases organizational productivity." Communications of the ACM 46(8): 8084.

[15] Neustaedter, C., et al. (2005). The Social Network and Relationship Finder: Social Sorting for Email Triage. CEAS.

[16] Stevens, G. R. and J. McElhill (2000). "A qualitative study and model of the use of e-mail in organisations." Internet Research 10(4): 271-283.

[17] ur Rehman, S. and V. Ramzy (2004). "Internet use by health professionals at the Health Sciences Centre of Kuwait University." Online Information Review 28(1): 53-60.

[18] Whittaker, S., et al. (2006). "Email in personal information management." Communications of the ACM 49(1): 68-73. 